\author{
C. Jaeger · N. Hauser · R. Gallinat · R. Kreienberg • \\ G. Sauer $\cdot$ R. Terinde
}

\title{
Cervical ectopic pregnancy: surgical or medical treatment?
}

Received: 22 January 2006 / Accepted: 8 June 2006 / Published online: 4 August 2006

(C) Springer-Verlag Berlin / Heidelberg 2006

\begin{abstract}
Cervical pregnancies are one of the rarest forms of ectopic gestations. The incidence of cervical ectopic pregnancies ranges between 1 in 1,000 to 95,000 gestations (Parente et al., Obstet Gynecol 62:79-82, 1983). Prior surgical trauma, including dilatation and curettage of the cervix, has been identified as one of the leading risk factors (Pisarska et al., Lancet 351:1115-1120, 1998; Yankowitz et al., Obstet Gynecol Surv 45:405-414, 1990). Cervical ectopic pregnancies are especially feared due to their associated life-threatening hemorrhage. Therefore, massive blood transfusions and emergency hysterectomy have often been required previously. Nevertheless, general guidelines for clinical management are lacking. In case reports medical and surgical treatment modalities are described. Overall, conservative management of an asymptomatic cervical ectopic pregnancy using methotrexate or potassium chloride seems to be superior to surgical intervention. The treatment of choice in patients suffering from symptomatic cervical ectopic pregnancy is still under discussion. In the case reported here, a combination of surgical and medical treatment conserving the patient's childbearing capacity was successfully implemented. However, severe hemorrhage occurred and consecutive blood transfusions were urgently necessary. Emergency hysterectomy could be avoided.
\end{abstract}

Keywords Cervical ectopic pregnancy .

Surgical treatment $\cdot$ Methotrexate

C. Jaeger $(\bowtie) \cdot$ N. Hauser $\cdot$ R. Gallinat $\cdot$ R. Kreienberg ·

G. Sauer $\cdot$ R. Terinde

Department of Obstetrics and Gynecology, University of Ulm, Prittwitzstrasse 43,

89075 Ulm, Germany

e-mail: christoph.jaeger@medizin.uni-ulm.de

Tel.: +49-731-50027575

Fax: +49-731-50027679

\section{Introduction}

Ectopic pregnancies (EP) are still a major problem, with more than 10,000 cases diagnosed annually in the UK [1]. The incidence of EP ranges between 1 and $2 \%$ of all gestations. Cervical pregnancy is one of the rarest ectopic gestations that accounts for $<1 \%$ of extrauterine pregnancies [2]. Cervical ectopic pregnancies (CEP) are especially feared due to their associated life-threatening transvaginal hemorrhage associated with the high risk of emergency hysterectomy and massive blood transfusions. In the past, hysterectomy was often the only choice available due to extensive and uncontrollable hemorrhage [3]. Nowadays, using high-resolution transvaginal sonography (TVS), the accuracy of the diagnosis of "cervical ectopic pregnancy" has significantly improved. Currently over $90 \%$ of EP can be visualized on TVS [4]. This means that EP can be diagnosed in an earlier stage when the woman is still asymptomatic. Therefore, not surgery but conservative medical treatment using methotrexate (MTX) or potassium chloride $(\mathrm{KCl})$ might be the more appropriate treatment modality. Still, there is no treatment of choice; in particular, for the management of more advanced CEP no "gold standard" has been established. We report a case of a nulliparous patient with CEP at 12 and 3/7 weeks gestation. A combination of conservative measures including surgical and medical procedures was successfully implemented. This case report discusses the diagnostic approach and therapeutic options available for the management of CEP in hemodynamically stable patients.

\section{Case report}

A 31-year-old nulliparous patient with vaginal bleedings and abdominal pain presented to her gynecologist. The first estimated gestational age was 9 and 5/7 weeks gestation according to the last menstrual period and the diagnosis of threatened abortion was made. The patient was referred for further evaluation and treatment to our institution. On initial TVS the patient was found to have a viable 12 and 
3/7 weeks gestation located at the endocervical canal. Her previous medical history was unremarkable, especially without any prior cervicouterine instrumentation or further risk factors for EP [5, 6]. Except for moderate vaginal bleedings neither sterile speculum nor physical examination revealed relevant information. By further TVS an empty uterine cavity with thickened endometrium was diagnosed. Approximately $1 \mathrm{~cm}$ from the external os of the cervical canal, an embryo with cardiac activity present and a crown-rump length (CRL) of $64 \mathrm{~mm}$ consistent with 12 and $3 / 7$ weeks gestation was depicted (Fig. 1). The chorion frondosum was located superiorly, just inferior to the internal cervical os. The patient was admitted for observation. The initial $\beta$-human chorionic gonadotropin (HCG) level was unknown. Treatment modalities were discussed with the patient. Due to the increase of vaginal bleeding surgical treatment was favored. Therefore, prostaglandin $\left(\right.$ Gemeprost ${ }^{\circledR}$ ) was administered as a vaginal suppository for cervical smoothening and then cervical dilatation and curettage was performed. During extraction of the conceptus massive hemorrhage occurred leading to an extensive blood loss of approximately 31 . Eight units of packed red cells were urgently transfused. Further units of fresh-frozen plasma, packed red cells, and thrombocyte concentrates were administered. Postoperative hematocrit was $20 \%$. Intraoperatively a prostaglandin-filled tamponade was placed into the cervical canal. Further profuse bleedings were controlled by the placement of a blocked Foley catheter into the endocervix. A "counter" tamponade of the rectum was performed to ensure sufficient compression and hemostasis. After $24 \mathrm{~h}$ the tamponade was removed and again profuse bleedings occurred from the implantation site in the endocervix. Another tamponade was necessary. In the following days after removal of the tamponade no more bleedings were evident. $\beta$-HCG levels dropped from 9,448 on day 4 after curettage to $682 \mathrm{mlU} / \mathrm{ml}$ on day 14 . The patient was discharged and controlled on an outpatient basis. On day 37 due to constant $\beta$-HCG levels $(86 \mathrm{mlU} / \mathrm{ml})$ the diagnosis of persistent trophoblastic tissue was made. Systemic MTX was administered (50 mg abs. i.v.). Afterwards $\beta$-HCG levels progressively decreased and the further clinical course was uneventful. Overall, the anatomic formation of the dilated cervix was significantly delayed (Figs. 2, 3).

Now, 2 years after therapy for CEP, this patient is pregnant again with an intrauterine singleton gestation.

\section{Discussion}

CEP is a rare obstetrical complication. CEP carries the considerable risk of maternal mortality or serious morbidity due to severe hemorrhage $[7,8]$. In the last decade, the improved accuracy of TVS led to the favorable fact that many cases of CEP are diagnosed preoperatively. It is still a central point in atypical ectopic pregnancies: for their safe therapeutic treatment an early diagnosis in asymptomatic women is necessary! The identification of CEP is mostly based upon a high degree of clinical suspicion confirmed by ultrasound examination [3, 9]. Sonographic findings include an empty uterus and a gestation filling the cervical canal (Fig. 1) [3]. The differential diagnosis of CEP is a prior intrauterine gestational sac in the process of being expelled from the uterine cavity. The main difference between these clinical situations is that in CEP the internal os of the cervical canal is closed, whereas in cervical
Fig. 1 Cervical ectopic pregnancy (TVS, 12 and 3/7 weeks gestation). Black arrows indicate the uterine corpus

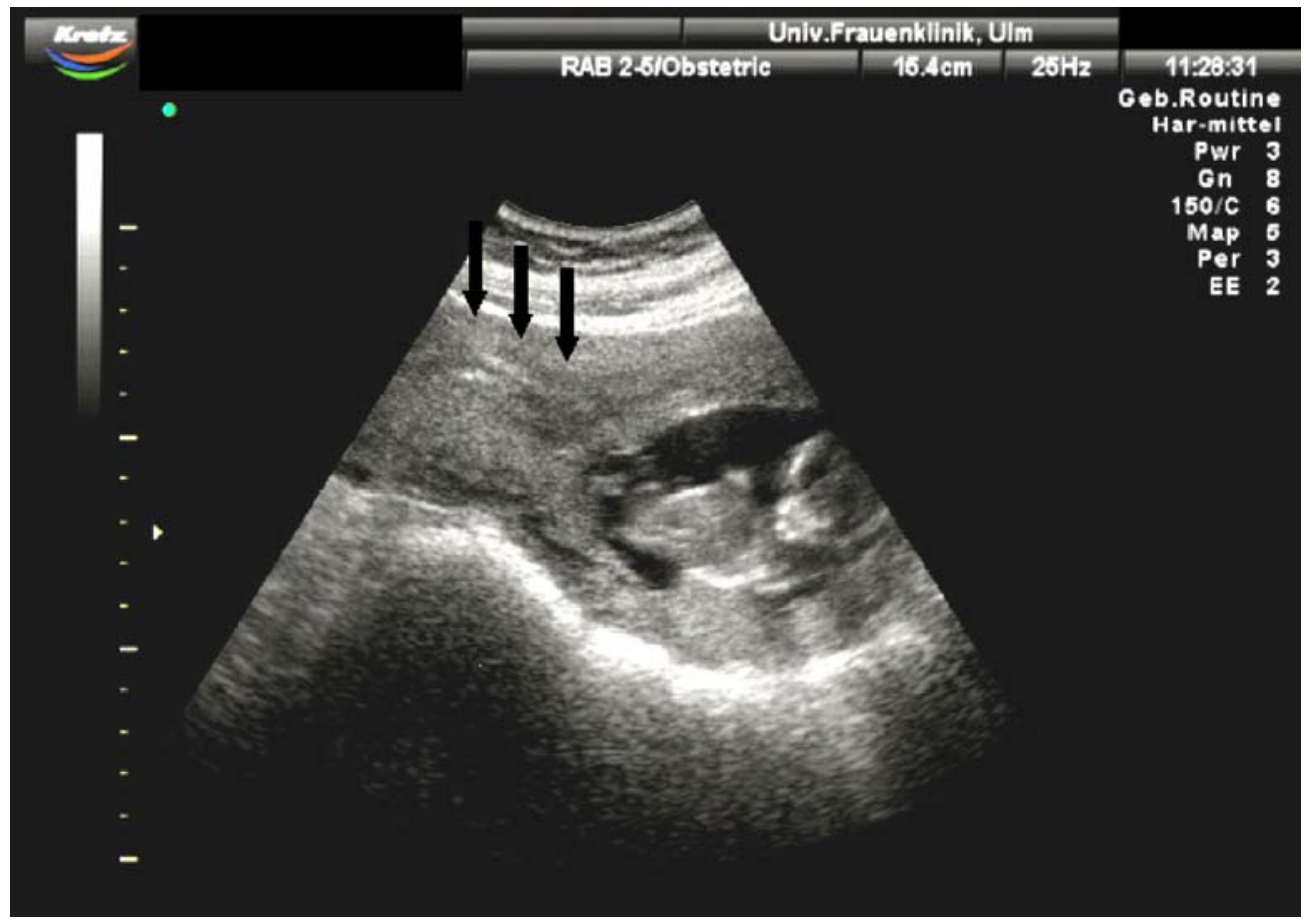


Fig. 2 Dilated cervical canal on day 15 after conservative surgery for CEP (TVS)

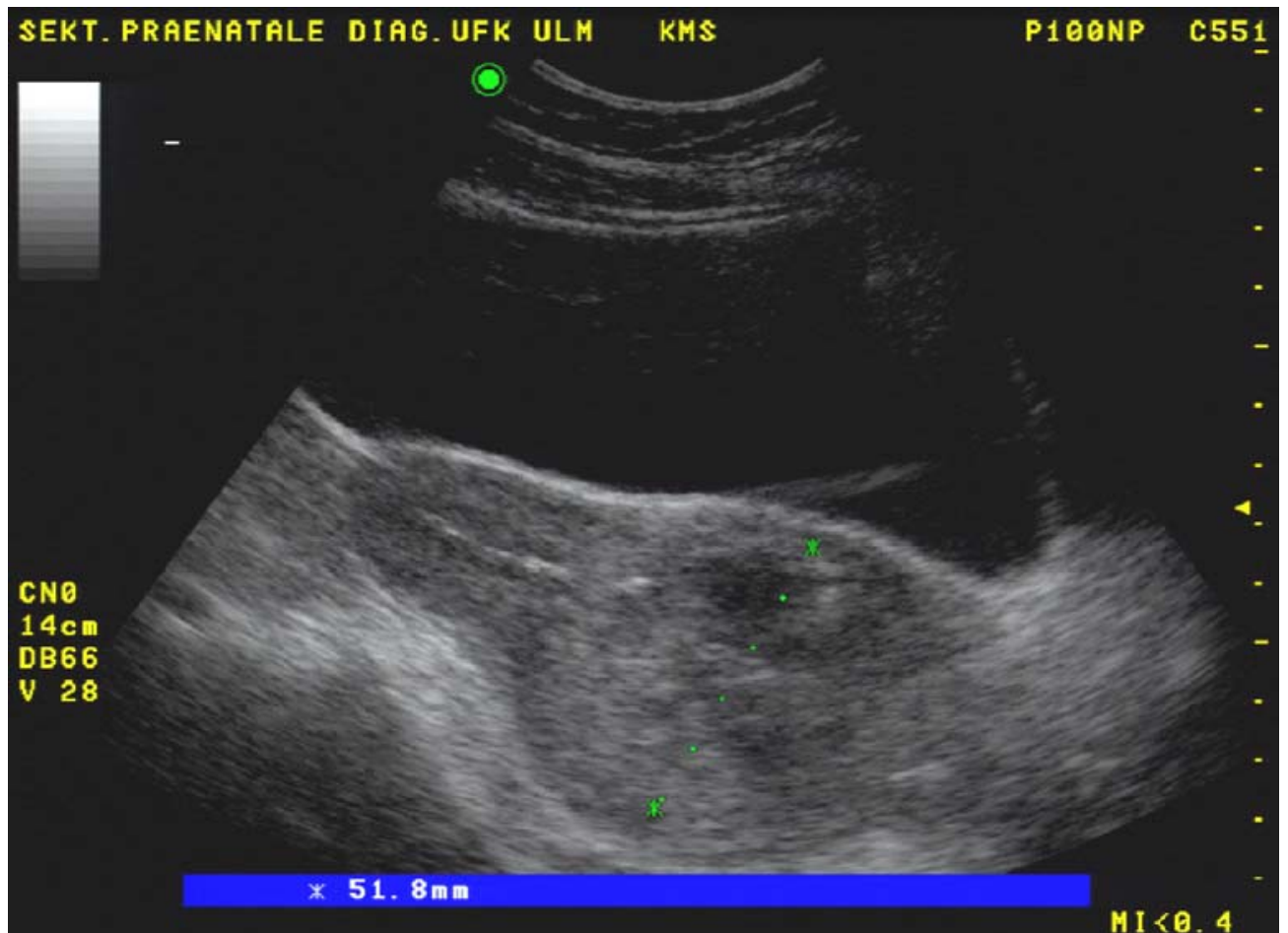

abortion it is dilated. If any doubt remains, magnetic resonance imaging is recommended [10].

The essential early diagnosis of CEP allows for careful planning of more conservative procedures in those patients who desire preservation of childbearing capacity [11]. For conservation of the uterus various therapeutic options are described including surgical ligation of blood vessels or artery embolization [9, 12-14], use of a Foley catheter to tamponade the endocervix after dilatation and curettage $[13,15,16]$, cervical cerclage $[15,17]$, and medical management with cytotoxic agents [11, 14, 18-22]. A review of the literature shows, although mainly consisting of case reports, that the present treatment standard in asymptomatic CEP is MTX combined with intra-amniotic
Fig. 3 Delayed anatomic formation of the still slightly dilated cervix on day 90 after conservative surgery for CEP (TVS)

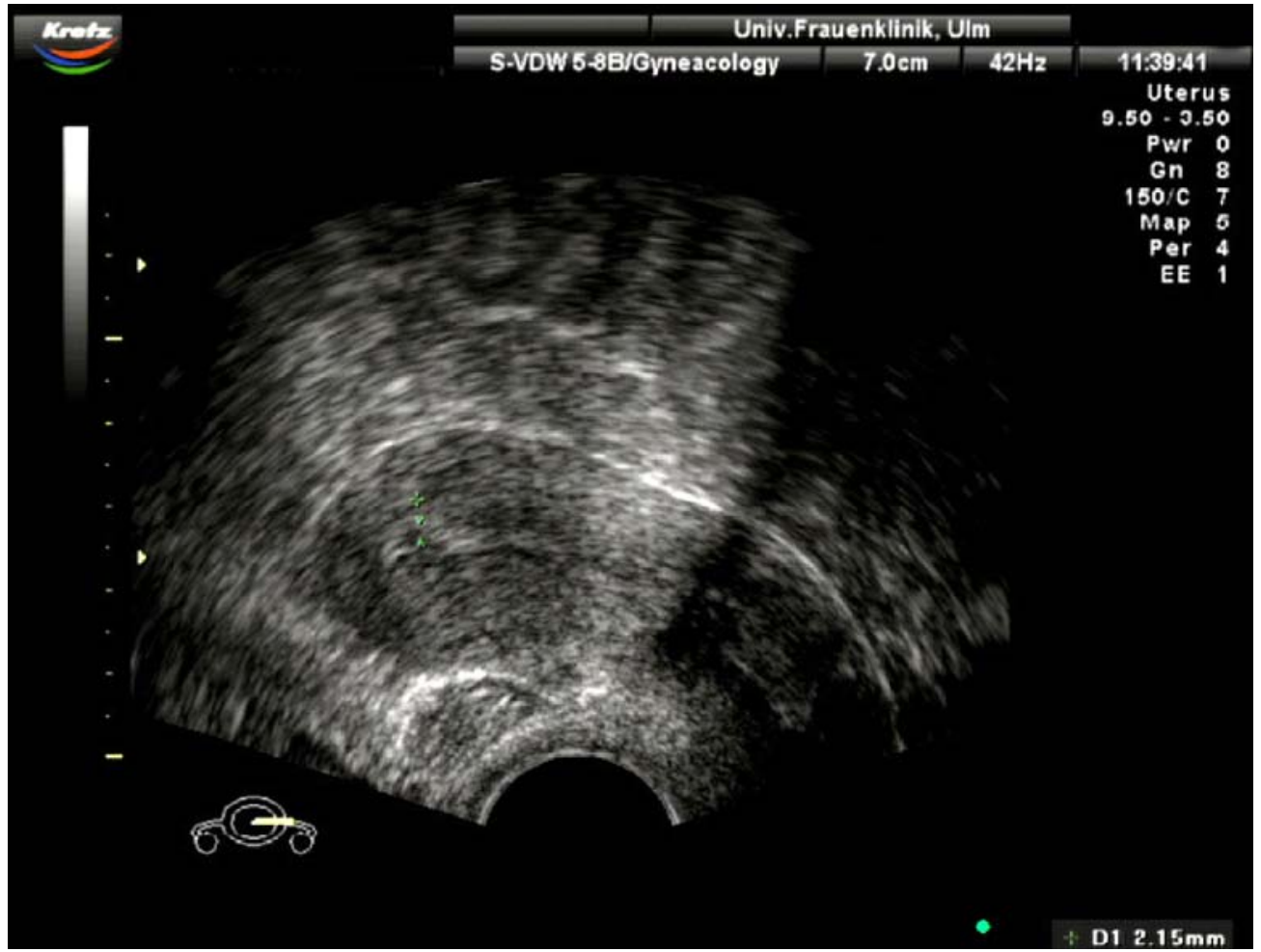


feticide in the case of a viable pregnancy $[23,24]$. Controversy remains about the criteria for a safe and successful medical or, on the other hand, surgical treatment. Many attempts are described to determine special risk factors predictive of the success rate of an either conservative or surgical procedure. The clinical conditions for the conservative medical approach were recently outlined in a noteworthy report by Ushakov et al. [23].

Risk factors for unsuccessful conservative medical management have been identified [25-27]. First, a serum $\beta$-HCG level of more than $10,000 \mathrm{mlU} / \mathrm{ml}$ and cardiac activity were found to be associated with higher treatment failure of MTX [25]. Second, Hung et al. have added two more prognostic factors indicating an elevated risk of treatment failure of MTX: $\geq 9$ weeks gestation and CRL $>10 \mathrm{~mm}[26,27]$. On the other hand, a review of the current literature reveals that there are some cases of advanced CEP with poor prognostic factors but an excellent clinical outcome after conservative medical treatment $[9,11,22$, $28,29]$.

This patient was symptomatic presenting with lower abdominal pain and moderate vaginal bleedings. The prognostic factors for successful medical treatment were unfavorable. Therefore, we elected to perform a conservative surgical procedure. The conservative surgical intervention using dilatation and curettage of the cervix led to significant vaginal bleedings. The availability and urgent use of massive blood transfusions was life-saving. Even though the childbearing capacity of this patient could be preserved, uncertainty remained about whether a more conservative primary medical management would have been more secure for the patient. In agreement with Mitra et al., we believe that also viable CEP of more than 10 weeks gestation can be treated successfully with medical therapy [11]. Moreover, in fetuses with cardiac activity it seems that intra-amniotic and/or intrafetal injection of MTX or $\mathrm{KCl}$ is usually necessary to reliably stop fetal cardiac activity and induce pregnancy resorption. Still, the most effective administration route of cytotoxic agents remains unclear. Frates et al. described the use of intrafetal or intra-amniotic $\mathrm{KCl}$ as a single agent in early CEP [9]. We agree with Hidalgo et al. that one weakness of MTX treatment is the inability to predict the occurrence of massive bleedings [27].

Generally, the need for primary surgical treatment in CEP increases with advancing gestational age $[7,8,11$, 30]. In this clinical situation significant and life-threatening vaginal hemorrhage remains the major concern. For the safe clinical management of advanced CEP some points must be outlined: in asymptomatic patients presenting with CEP primary conservative medical management using MTX or $\mathrm{KCl}$ is always a possible treatment option. At any time when treating a patient with CEP, a considerable amount of packed red blood cells must be held in reserve. Furthermore, local or systemic measures ensuring hemostasis such as cervical tamponade or blockade using a Foley catheter, percutaneous embolization of pelvic vessels, or surgical ligation of cervical branches of uterine arteries must be available immediately. Urgent laparotomy must be possible at any time.

In summary, there are no guidelines available for clinicians. Therefore, each case of CEP must be managed individually taking the presented management modalities carefully into account.

\section{References}

1. "Why mothers die," triennial report 2000-2002. Confidential enquiry into maternal deaths, UK

2. Parente JT, Ou CS, Levi J, Legatt E (1983) Cervical pregnancy analysis: a review and report of five cases. Obstet Gynecol 62:79-82

3. Cunningham FG, Gant NF, Leveno KJ, Gilstrap LC III, Hauth JC, Wenstrom KD (2001) Ectopic pregnancy, chapter 24. In: Williams obstetrics, 21st edn. McGraw-Hill, New York, pp 884-910

4. Condous G, Okaro E, Khalid A, Lu C, Van Huffel S, Timmerman D, Bourne T (2005) The accuracy of transvaginal ultrasonography for the diagnosis of ectopic pregnancy prior to surgery. Hum Reprod 20:1404-1409

5. Pisarska MD, Carson SA, Buster JE (1998) Ectopic pregnancy. Lancet 351:1115-1120

6. Yankowitz J, Leake J, Huggins G, Gazaway P, Gates E (1990) Cervical ectopic pregnancy: review of the literature and report of a case treated by single-dose methotrexate therapy. Obstet Gynecol Surv 45:405-414

7. Sivaligam N, Mak FK (2000) Delayed diagnosis of cervical pregnancy: management options. Singapore Med J 41:599-601

8. Tuncer R, Uygur D, Kis S, Kayin S, Bebitoglu I, Erkaya S (2001) Inevitable hysterectomy despite conservative surgical management in advanced cervical pregnancy: a case report. Eur J Obstet Gynecol Reprod Biol 100:102-104

9. Frates MC, Benson CB, Doubilet PM et al (1994) Cervical ectopic pregnancy: results of conservative treatment. Radiology 191:773-775

10. Bader-Armstrong B, Shah Y, Rubens D (1989) Use of ultrasound and magnetic resonance imaging in the diagnosis of cervical pregnancy. J Clin Ultrasound 17:283-286

11. Mitra AG, Harris-Owens M (2000) Conservative medical management of advanced cervical ectopic pregnancies. Obstet Gynecol Surv 55:385-389

12. Ratten GJ (1983) Cervical pregnancy treated by ligation of the descending branch of the uterine arteries: case report. $\mathrm{Br} \mathrm{J}$ Obstet Gynaecol 90:367-371

13. Saliken JC, Normore WJ, Pattinson HA, Wood S (1994) Embolization of the uterine arteries before termination of a 15week cervical pregnancy. Can Assoc Radiol J 45:399-401

14. Cosin JA, Bean M, Grow D, Wiczyk H (1997) The use of methotrexate and arterial embolization to avoid surgery in a case of cervical pregnancy. Fertil Steril 67:1169-1171

15. Bachus KE, Stone D, Suh B, Thickman D (1990) Conservative management of cervical pregnancy with subsequent fertility. Am J Obstet Gynecol 162:450-451

16. Reginald PW, Reid JE, Paintin DB (1985) Control of bleeding in cervical pregnancy: two case reports. Br J Obstet Gynaecol 92:1199-1200

17. Wharton KR, Gore B (1988) Cervical pregnancy managed by placement of a Shirodkar cerclage before evacuation. A case report. J Reprod Med 33:227-229

18. Chew S, Anandakumar C (2001) Medical management of cervical pregnancy - a report of two cases. Singapore Med J 42:537-539

19. Goldberg JM, Widrich T (2000) Successful management of a viable cervical pregnancy by single-dose methotrexate. J Womens Health Gend Based Med 9:43-45 
20. Margolis K (2000) Cervical pregnancy treated with a single intravenous administration of methotrexate plus oral folinic acid. Aust N Z J Obstet Gynaecol 40:347-349

21. Stovall TG, Ling FW, Smith WC, Felker R, Rasco BJ, Buster JE (1988) Successful nonsurgical treatment of cervical pregnancy with methotrexate. Fertil Steril 50:672-674

22. Kung FT, Chang SY (1999) Efficacy of methotrexate treatment in viable and nonviable cervical pregnancies. Am J Obstet Gynecol 181:1438-1444

23. Ushakov FB, Elchalal U, Aceman PJ et al (1996) Cervical pregnancy: past and future. Obstet Gynecol Surv 52:45

24. Riethmuller D, Courtois L, Maillet R, Schaal JP (2003) Ectopic pregnancy management: cervical and abdominal pregnancies. J Gynecol Obstet Biol Reprod (Paris) 32:S101-S108

25. Bai SW, Lee JS, Park JH, Kim JY, Jung KA, Kim SK, Park KH (2002) Failed methotrexate treatment of cervical pregnancy. Predictive factors. J Reprod Med 47:483-488
26. Hung TH, Shau WY, Hsieh TT, Hsu JJ, Soong YK, Jeng CJ (1998) Prognostic factors for an unsatisfactory primary methotrexate treatment of cervical pregnancy: a quantitative review. Hum Reprod 13:2636-2642

27. Hidalgo LA, Penafiel J, Chedraui PA (2004) Management of cervical pregnancy: risk factors for failed systematic methotrexate. J Perinat Med 32:184-186

28. Brand E, Gibbs RS, Davidson SA (1993) Advanced cervical pregnancy treated with actinomycin-D. Br J Obstet Gynaecol 100:491-492

29. Wolcott HD, Kaunitz AM, Nuss RC, Benrubi GE (1988) Successful pregnancy after previous conservative treatment of an advanced cervical pregnancy. Obstet Gynecol 71:1023-1025

30. Honda T, Hasegawa M, Nakahori T, Maeda A et al (2005) Perinatal management of cervicoisthmic pregnancy. J Obstet Gynaecol Res 31:332-336 